\title{
Case report and summary of literature: giant perineal keloids treated with post-excisional radiotherapy Kristin Jones ${ }^{1}$, Clifton D Fuller*1, Join Y Luh ${ }^{1}$, Craig C Childs ${ }^{2}$, Alexander R Miller ${ }^{3}$, Anthony W Tolcher ${ }^{3}$, Terence S Herman ${ }^{4}$ and Charles R Thomas Jr ${ }^{5}$
}

Address: ${ }^{1}$ Department of Radiation Oncology, University of Texas Health Science Center- San Antonio, San Antonio, USA, ${ }^{2}$ Private Practice, San Antonio, TX, USA, ${ }^{3}$ Institute for Drug Development, Cancer Therapy and Research Center, San Antonio, USA, ${ }^{4}$ Department of Radiation Oncology, University of Oklahoma Health Sciences Center, Oklahoma City, USA and ${ }^{5}$ Department of Radiation Oncology, Oregon Health \& Science University, Portland, USA

Email: Kristin Jones - joneskc@uthscsa.edu; Clifton D Fuller* - fullercd@uthscsa.edu; Join Y Luh - jluh@ctrc.net;

Craig C Childs - cchilds@mindspring.com; Alexander R Miller - amiller@ctrc.net; Anthony W Tolcher - atolcher@ctrc.net; Terence S Herman - HERMANT@UTHSCSA.EDU; Charles R Thomas - thomasch@ohsu.edu

* Corresponding author

Published: 19 April 2006

BMC Dermatology 2006, 6:7 doi:10.1 I86/147/-5945-6-7
Received: 05 May 2005

Accepted: 19 April 2006

This article is available from: http://www.biomedcentral.com/147I-5945/6/7

(c) 2006 Jones et al; licensee BioMed Central Ltd.

This is an Open Access article distributed under the terms of the Creative Commons Attribution License (http://creativecommons.org/licenses/by/2.0), which permits unrestricted use, distribution, and reproduction in any medium, provided the original work is properly cited.

\begin{abstract}
Background: Keloids are common benign tumors of the dermis, typically arising after insult to the skin. While typically only impinging on cosmesis, large or recurrent keloids may require therapeutic intervention. While no single standardized treatment course has been established, several series report excellent outcomes for keloids with post-surgery radiation therapy.

Case presentation: We present a patient with a history of recurrent keloids arising in the absence of an ascribed trauma and a maternal familial history of keloid formation, whose physical examination several large perineal keloids of $6-20 \mathrm{~cm}$ in the largest dimension. The patient was treated with surgical extirpation and adjuvant radiation therapy. Radiotherapy was delivered to the scar bed to a total dose of 22 Gy over II daily fractions. Acute radiotherapy toxicity necessitated a treatment break due to RTOG Grade III acute toxicity (moderate ulceration and skin breakdown) which resolved rapidly during a 3-day treatment break. The patient demonstrated local control and has remained free of local recurrence for more than 2 years.
\end{abstract}

Conclusion: Radiotherapy for keloids represents a safe and effective option for post-surgical keloid therapy, especially for patients with bulky or recurrent disease.

\section{Background}

Keloids are benign, common, fibroproliferative dermal tumors which usually occur as a result of trauma to the skin[1], though their pathogenesis is distinct from hypertrophic scars [2]. Keloids are often refractory to treatment, recurring frequently. While the precise etiology and genetic mechanism of this pathology is unknown, keloids are believed to be more prevalent in patients of African descent. While most keloids are sporadic, familial keloids seem to represent an incomplete penetrance autosomal dominant disease, with varying degrees of clinical severity within a pedigree [3]. An association with diabetes, which 
was noted in the medical history of our patient and her maternal line, has also been observed in at least one series [4]. Additionally, this case is remarkable for the fact that few keloids form in the female genital region in comparison to other high-skin tension regions, for unknown reasons [5]. While not frequently considered as candidates for oncologic therapies, severe lesions may require radiotherapy or intralesional injection of interferon and flourouracil in addition to surgical extirpation [2-4]. This case presents the formation of keloids without recollection of any recollected traumatic event, notable for their location and size, in a female patient subsequently treated with post-surgical radiotherapy.

\section{Case presentation}

A 34-year old African-American woman presented with a giant perineal tumor associated with a 29-year history of keloid formation without recalled dermal injury or abrasion. The patient's history revealed two family members (a mother and sister) with similar symptomology, resulting in a diagnosis of familial keloid syndrome. However, neither the mother nor sister was affected with perineal keloid development. Past medical history was also notable for arthritic symptoms and diabetes mellitus, which were present in both mother and sister. The index lesion was firm, pliable growth, $20 \mathrm{~cm}$ in its greatest diameter, adjacent to $10 \mathrm{~cm}$ and $6 \mathrm{~cm}$ perivulvar lesions, which caused the patient considerable discomfort and affected ambulation (Figure 1). Physical examination revealed multiple other hypertrophic nodular growths on the posterior neck, behind the right ear, bilateral scapular regions, right flank and breast, abdomen and extremities in addition to the primary lesion. Past medical history evinced numerous heterogeneous treatments for various keloids in multiple loci; she had previously received surgical extirpation, steroid injections, and two episodes of radiotherapy to the back. Despite these interventions, her keloids have either recurred or persisted. Surgical extirpation of the largest perineal lesion was undertaken, and histopathologic examination was performed, denoting the classic keloid-associated features of haphazard collagen deposition, with nodular formations thickened hyalinized bands (Figure 2).

On the day following surgical excision, the patient was treated with radiotherapy using photons at $6 \mathrm{MV}$. The total dose delivered was 22 Gy in 11 days, with a daily fraction of $2 \mathrm{~Gy}$. The dose fraction was split between two fields with an anterior-posterior/posterior-anterior ( $\mathrm{AP} / \mathrm{PA})$ port arrangement. Maximum acute Radiation Therapy Oncology Group skin toxicity score was Grade 3 (moderate ulceration and skin breakdown), which resolved after a 3-day treatment break.

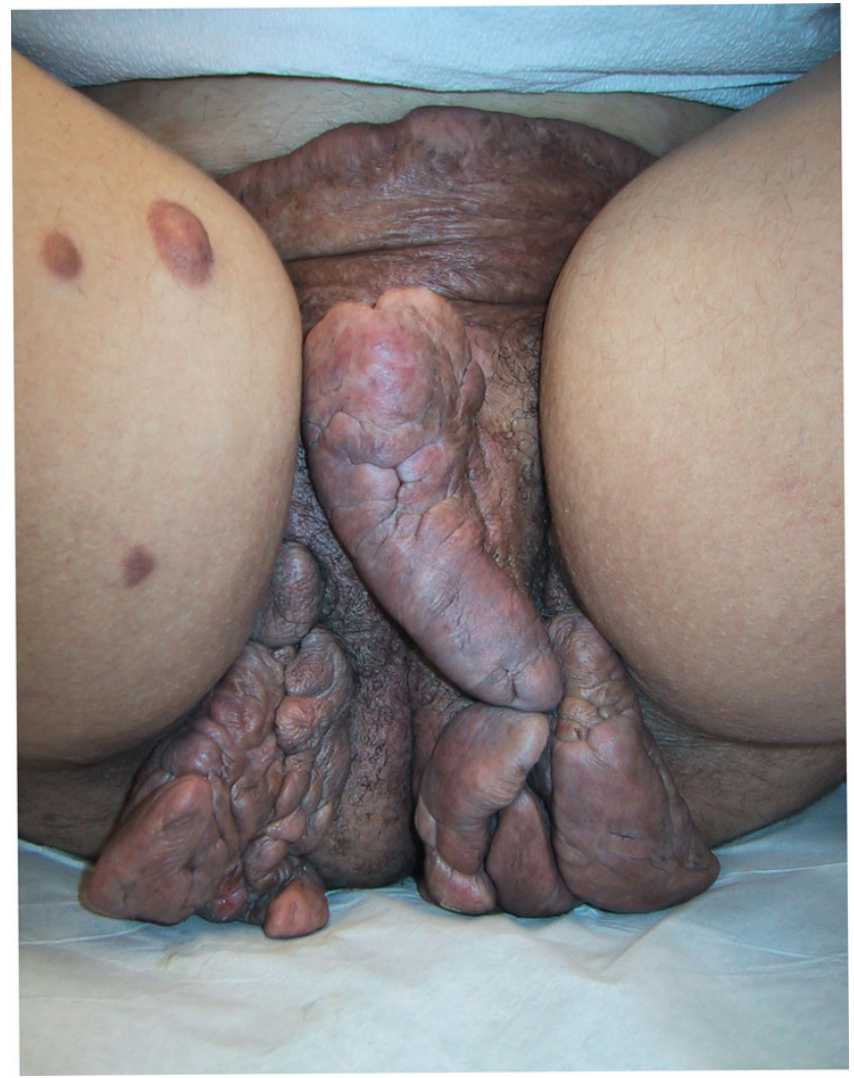

\section{Figure I}

Pre-therapy photograph of giant perineal keloid, showing lobulated appearance.

At 6 months post-therapy, the lesion in question had not recurred (Figure 3), and the patient reported no difficulty attributable to the lesion.

After 10 months after completion of radiation treatment for perineal keloids, the patient returned for additional treatment to her back and chest wall. Radiotherapy was delivered at $3 \mathrm{~Gy} /$ fraction with $9 \mathrm{MeV}$ electrons to her back, lateral back, and anteromedial back over 4 days. No complications have been noted, and the patient is currently being followed, with $>24$ months since therapy..

\section{Conclusion}

Keloids are benign fibroproliferative growths distinguished by excessive collagen deposition in the dermis. The exact etiology of these lesions remains unknown. They are considered a derailment of the normal wound healing process with a higher prevalence in darker pigmented races.

Keloids are often described as benign fibroproliferative growths resulting from a connective tissue response to a variety of insults, such as surgery, burns, trauma, inflam- 


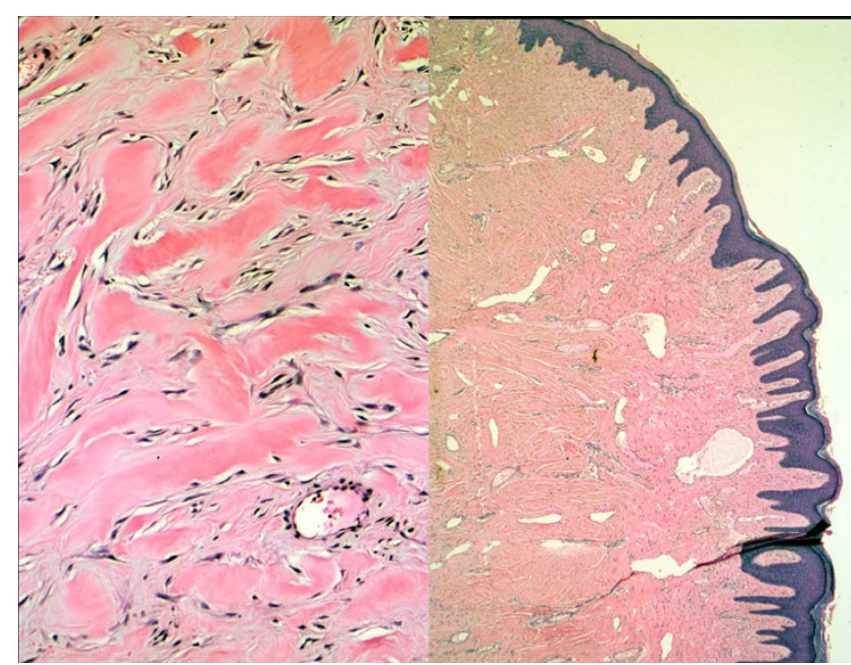

\section{Figure 2}

Low (right)- and high-power histology of excised keloid, showing characteristic grayish-colored lobular tissue with fibrous polypoid whorls.

mation, foreign-body reactions, endocrine dysfunction. However, they occasionally occur without apparent external cause. They are characterized by excessive collagen and glycosaminoglycan deposition within the dermis, an increase in collagen turnover, and micro-vasculature regeneration $[6,9,10]$. Clinically, keloids may not appear

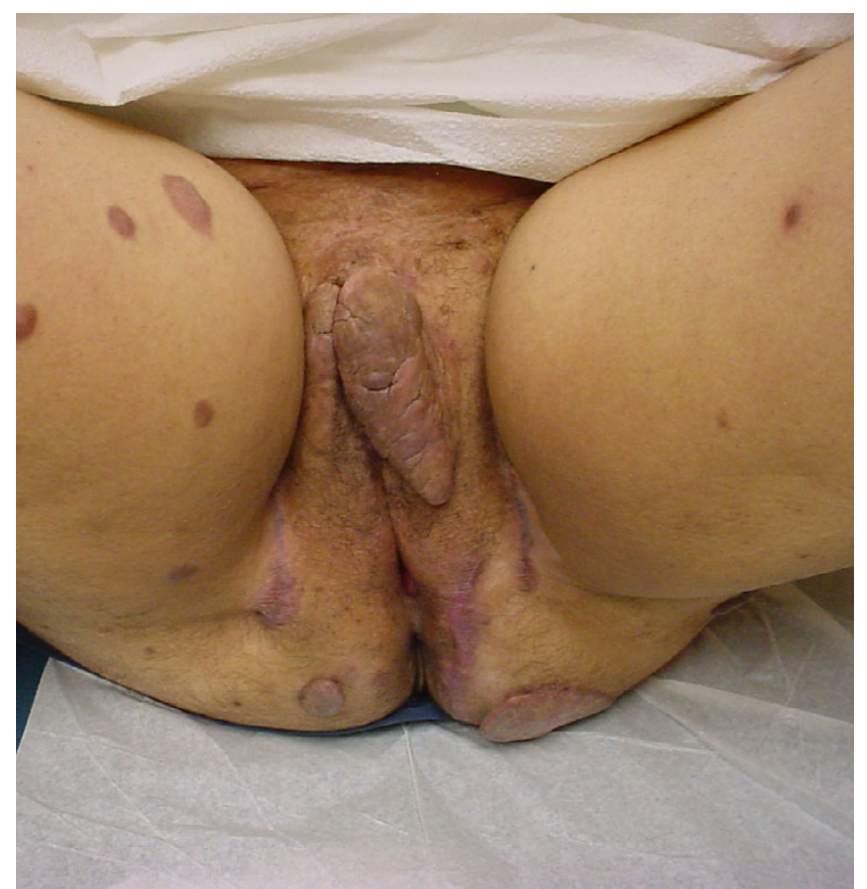

\section{Figure 3}

Three-month follow-up appearance after surgical excision and radiotherapy. for several months and can be delayed for several years after initial injury. Minor injuries can produce a fairly large, deep, and reddish-purple indurated lesion that rarely subsides. They can range in size from small papules limited to only a few millimeters in diameter to football size and larger. Their texture can vary between a soft and dough-like to a hard and rubbery consistency. These lesions most commonly affect areas of increased skin tension. Very rarely, keloids may develop on the palms of the hands, soles of the feet, and the genitalia [5].

Keloid formation can be found in all ethnicities, but has a higher predilection for darker pigmented populations. Why occurrence rates are higher among these groups as opposed to others is inconclusive. Inheritance patterns may offer clues as to who could be at a greater risk of being predisposed to forming these types of lesions. Several reports have suggested that keloids follow an autosomal dominant or autosomal recessive inheritance pattern, although the exact mode of inheritance remains unknown. Maneros et al. report observing 14 pedigrees with familial keloids that spanned 3 generations [5]. While most families in the study where African-American, the report concludes that this may be associated more ethnicity rather than skin pigment, since some lighterskinned members of the families had the more severe lesions. Through the use of a genome wide linkage screen, plausible gene loci for these keloid pedigrees were identified [6]. Their results found a pattern consistent with an autosomal dominant mode of inheritance. Subsequent linkage analysis has revealed two distinct gene loci which may serve as specific susceptibility genes [11].

In keloid lesions, the therapy chosen is predicated upon several factors, including: size of lesion, location, depth of lesion, age of patient, and past response to treatment. Surgical excision, radiation, pressure therapy, cryotherapy, intralesional injections of corticosteroids, interferon and fluorouracil, topical silicone and other dressings, and pulse-dye laser treatment have all been found to induce some degree of regression [12]. Despite the broad range of treatment modalities, there is no universally accepted treatment protocol. In most instances these therapies are used as an adjuvant to surgical excision.

Radiation therapy has been a rather controversial issue in keloid treatment. Surgery-alone and adjuvant intralesional corticosteroid approaches exhibit literature reported recurrence rates of $45-100 \%$ and under $50 \%$, respectively [7]. Comparatively, extant radiotherapy series have demonstrated recurrence rates which are markedly better than surgery alone or adjuvant corticosteroid injection. A brief summary of selected English language series of teletherapy treatment for keloids are collated in Table 1 . However, the only prospective randomized trial of any 
Table I: Summary of selected literature (WLE = wide local excision; $R T$ = radiotherapy; $F x=$ fraction).

\begin{tabular}{|c|c|c|c|c|c|c|c|c|}
\hline Author & Subset & Pts & \# Lesions & Technique & Response rate(\%) & $\begin{array}{l}\text { Total dose } \\
\text { (Gy) }\end{array}$ & $\begin{array}{l}\text { Fx size } \\
(G y)\end{array}$ & Notes/findings \\
\hline Arnold[13] & All & 155 & 179 & Superficial X-rays & & $10-30$ & $2-7$ & Historical series demonstrates results of RT without surgery \\
\hline & RT only & & 67 & $"$ & 81 & $10-30$ & $2-7$ & \\
\hline & $W L E+R T$ & & 52 & $"$ & 79 & $10-30$ & $2-7$ & \\
\hline Chaudhry[14] & $W L E+R T$ & 36 & - & Superficial X-rays & 97 & 18 & 3 & Series are earlobe keloids only. \\
\hline Borok $[15]$ & $W L E+R T$ & 250 & 393 & Superficial X-rays & 98 & $4-16$ & varied & Excellent cosmetic results in $92 \%$ of pts; recommended 12 Gy in $3 \mathrm{fx}$. \\
\hline Doornbos[3] & $\mathrm{RT}$ alone/WLE + RT & 203 & 278 & Superficial X-rays & 74 & $4.5-18$ & varied & $\begin{array}{l}\text { Risk of failure necessitates total dose of at least } 9 \mathrm{~Gy} \text {. } 15 \text { pts got definitive } \\
\text { RT. } 9 \text { Gy resulted in } 70.4 \% \text { control rate vs. } 36.4 \% \text { with } 6 \mathrm{~Gy} \text {. }\end{array}$ \\
\hline Lo[16] & $W L E+R T$ & 199 & 354 & Electrons & - & $2-20$ & 1 & $\begin{array}{l}\text { Single fraction regimen; local control of } 87 \% \text { receiving doses of } 9 \text { Gy or } \\
\text { greater, vs } 43 \% \text { of } 21 \text { receiving less than } 9 \mathrm{~Gy} \text {, though non-significant } \\
\text { statistically. }\end{array}$ \\
\hline Kovalic[17] & $W L E+R T$ & 75 & 113 & Superficial X-rays & 73 & $10-20$ & $1-5$ & Mixed treatment cohort; no need to give RT within 24 hours \\
\hline Levy[18] & $W L E+R T$ & 37 & - & Superficial X-rays & 88 & $15-18$ & $5-6$ & $4 / 37$ pts exhibited "fair or poor results" \\
\hline Enhamre[19] & $W L E+R T$ & 47 & 62 & Superficial X-rays & 88 & $10-15$ & $1-3$ & No statistical difference in pts. treated 3 vs 14 days post-excision. \\
\hline Ogawa[20] & $W L E+R T$ & 129 & 147 & electrons & 67 & 15 & 5 & Numerically large series with single dose protocol \\
\hline Klumpar[2I] & $W L E+R T$ & 83 & 126 & Mixed & 78 & & & $\begin{array}{l}\text { Study demonstrates electron beam offers no advantage over orthovoltage } \\
\text { therapy }\end{array}$ \\
\hline & & & 73 & $\begin{array}{l}\text { Orthovoltage } X- \\
\text { rays }\end{array}$ & 85 & & & \\
\hline & & & 53 & electrons & 79 & & & \\
\hline Maarouf[9] & $W L E+R T$ & 100 & 134 & electrons & 84 & $9-15$ & $3-5$ & \\
\hline Malaker[22] & RT alone & 64 & 86 & $\begin{array}{l}\text { Superficial X- } \\
\text { rays/electrons }\end{array}$ & 97 & 37.5 & 5 & $\begin{array}{l}\text { All pts had unresectable keloids; } 63 \% \text { of patients were pleased with } \\
\text { treatment outcome }\end{array}$ \\
\hline $\begin{array}{l}\text { Ragoowansi }[1 \\
\text { 2] }\end{array}$ & $W L E+R T$ & 80 & 80 & Superficial X-rays & 84 & 10 & 1 & $\begin{array}{l}100 \% \text { control at } 4 \text { weeks follow-up; } 91 \% \text { relapse free at I yr; } 84 \% \text { relapse } \\
\text { free at } 5 \text {-years. }\end{array}$ \\
\hline Sallstrom[23] & $W L E+R T$ & 124 & - & Superficial X-rays & 92 & 18 & 3 & At 24 months $93 \%$ of patients found therapy worthwhile. \\
\hline Sclafani[8] & $W L E+R T$ & 16 & - & Superficial X-rays & 88 & $7-10$ & 1 & $\begin{array}{l}\text { RT arm of randomized trial vs. corticosteroid injection; greater } \\
\text { compliance and ease of treatment with RT. }\end{array}$ \\
\hline
\end{tabular}


kind for keloids demonstrated greater control rates for surgical excision and radiotherapy compared to surgery and corticosteroid injection, with recurrence rates of $12.5 \%$ after surgery and radiation therapy, versus 33\% after surgery and steroid injections, though with a statistically non-significant mean differential [8]. The favorable outcomes with this approach are attributable to destruction of keloid fibroblasts by ionizing radiation, which has been shown to enhance apoptosis when given in small to moderate doses. In a study by Luo et al., gamma radiation was found to cause a 2-fold increase in the density of apoptotic cells in both normal and keloid tissue [13]. According to a study by Ragoowansi et al., using $60 \mathrm{kV}$ photon irradiation of $10 \mathrm{~Gy}$ in a single fraction to treat 80 keloids in 80 patients, the majority of keloids can be controlled by a single operation with immediate adjuvant single-fraction radiotherapy [14]. Unresectable keloids can also be treated satisfactorily with radiotherapy, as Malaker et al. demonstrated by treating 64 patients with 86 unresectable keloids with 37.5 Gy was given in 5 fractions over a 5-week period[15]. By 18 months $97 \%$ of patients had complete regression and 3\% had partial regression. Surveyed, $63 \%$ of patients were happy with the outcome. Additional series have concurred that recurrent keloids may be successfully treated with the radiotherapy postexcision [16], and have also explored brachytherapy as an option for patients failing primary therapy [17]. Electron radiotherapy has also been used with good result. Maarouf et al. report a series of 134 keloids treated following surgical excision, with an $84 \%$ control rate) and minimal side effects, with a mean follow-up period of 7.2 years [9]. Ogawa et al followed 129 keloid cases for 18 or more months after post-operative irradiation with $4-\mathrm{MeV}$ electron beam radiation of $15 \mathrm{~Gy}$ [19]. With a median followup period of 24 months, there was an overall $32.7 \%$ recurrence rate. The most common side effects of radiotherapy consist of hyperpigmentation, pruritis, and erythema. Additionally, there is a small, but notable, stochastic risk for future secondary malignancy inherent in any radiation exposure. However, at present, few series have exhibited notable secondary carcinogenesis[10]; Dinh et al. [11] note that in a cumulative review by Ragoowansi [12] five (5) possible secondary malignancies were noted in 6,741 treated keloids, for crude risk of 1/1,348 patients, according to the literature. Consequently, patients must be informed and radiotherapy used judiciously, and with careful follow-up of patients over the course of their lives.

While no optimum treatment modality has been demonstrated for recurrent keloids in adults, surgical resection and adjuvant radiation therapy may provide an effective option, with notable clinical success rates. In summary, radiotherapy is, while not without risk, an exceedingly effective primary adjuvant or salvage therapy for some keloids (particularly large and recurrent tumors). Radiother- apy has been shown in extant series to exhibit better results than the other notable adjuvant therapy of choice, corticosteroid injection [8], with a secondary malignancy risk that is minimal enough such that it should not preclude utilization $[10,11]$.

\section{Competing interests}

The author(s) declare that they have no competing interests.

\section{Authors' contributions}

$\mathrm{KJ}$ and $\mathrm{CF}$ drafted the manuscript. $\mathrm{CF}, \mathrm{JL}, \mathrm{TH}, \mathrm{CC}$, AM and AT attended to the patient, participated in the design of the case report, and edited the manuscript. CF conceived the study. CT participated in its design and coordination. All authors read and approved the final manuscript.

\section{Acknowledgements}

First and foremost, we wish to thank our patient; written consent was obtained from the patient for publication of this study. We also wish to thank David Hussey, MD, and Sean Cavanaugh, MD, for their constructive critiques.

\section{References}

I. English RS, Shenefelt PD: Keloids and hypertrophic scars. Dermatol Surg 1999, 25(8):63I-638.

2. Berman B, Flores F: The treatment of hypertrophic scars and keloids. Eur J Dermatol 1998, 8(8):591-595.

3. Doornbos JF, Stoffel TJ, Hass AC, Hussey DH, Vigliotti AP, Wen BC, Zahra MK, Sundeen V: The role of kilovoltage irradiation in the treatment of keloids. Int J Radiat Oncol Biol Phys 1990, I 8(4):833-839.

4. Alster TS, Tanzi EL: Hypertrophic scars and keloids: etiology and management. Am J Clin Dermatol 2003, 4(4):235-243.

5. Marneros AG, Norris JE, Olsen BR, Reichenberger E: Clinical genetics of familial keloids. Arch Dermatol 200I, I37(I I): | 429- I 434.

6. Marneros AG, Norris JE, Watanabe S, Reichenberger E, Olsen BR: Genome scans provide evidence for keloid susceptibility loci on chromosomes 2q23 and 7plI. J Invest Dermatol 2004, I 22(5): I | 26-I | 32.

7. Berman B, Bieley HC: Adjunct therapies to surgical management of keloids. Dermatol Surg 1996, 22(2): I 26- I 30.

8. Sclafani AP, Gordon L, Chadha M, Romo T 3rd: Prevention of earlobe keloid recurrence with postoperative corticosteroid injections versus radiation therapy: a randomized, prospective study and review of the literature. Dermatol Surg 1996, 22(6):569-574.

9. Maarouf M, Schleicher U, Schmachtenberg A, Ammon J: Radiotherapy in the management of keloids. Clinical experience with electron beam irradiation and comparison with $X$-ray therapy. Strahlenther Onkol 2002, I 78(6):330-335.

10. Botwood N, Lewanski C, Lowdell C: The risks of treating keloids with radiotherapy. BrJ Radiol I999, 72(864): I222-I 224.

II. Dinh Q, Veness $M$, Richards S: Role of adjuvant radiotherapy in recurrent earlobe keloids. Australas J Dermatol 2004, 45(3): $162-166$.

12. Ragoowansi R, Cornes PG, Moss AL, Glees JP: Treatment of keloids by surgical excision and immediate postoperative single-fraction radiotherapy. Plast Reconstr Surg 2003, I I I (6): 1853-1859.

13. Arnold HL Jr, Grauer FH: Keloids: etiology, and management by excision and intensive prophylactic radiation. Arch Dermatol 1959, 80:772-777.

14. Chaudhry MR, Akhtar S, Duvalsaint F, Garner L, Lucente FE: Ear lobe keloids, surgical excision followed by radiation therapy: a I0-year experience. Ear Nose Throat J 1994, 73(1 0):779-78I. 
15. Borok TL, Bray M, Sinclair I, Plafker J, LaBirth L, Rollins C: Role of ionizing irradiation for $\mathbf{3 9 3}$ keloids. Int J Radiat Oncol Biol Phys 1988, I5(4):865-870.

16. Lo TC, Seckel BR, Salzman FA, Wright KA: Single-dose electron beam irradiation in treatment and prevention of keloids and hypertrophic scars. Radiother Oncol 1990, 19(3):267-272.

17. Kovalic JJ, Perez CA: Radiation therapy following keloidectomy: a 20-year experience. Int J Radiat Oncol Biol Phys 1989, I 7(I):77-80.

18. Levy DS, Salter MM, Roth RE: Postoperative irradiation in the prevention of keloids. AJR Am J Roentgenol 1976, I 27(3):509-510.

19. Enhamre A, Hammar H: Treatment of keloids with excision and postoperative X-ray irradiation. Dermatologica 1983, 167(2):90-93.

20. Ogawa R, Mitsuhashi K, Hyakusoku H, Miyashita T: Postoperative electron-beam irradiation therapy for keloids and hypertrophic scars: retrospective study of 147 cases followed for more than 18 months. Plast Reconstr Surg 2003, I I I(2):547-553. discussion 554-545

21. Klumpar DI, Murray JC, Anscher M: Keloids treated with excision followed by radiation therapy. J Am Acad Dermatol I 994, 3 I (2 Pt I):225-23I.

22. Malaker K, Vijayraghavan K, Hodson I, Al Yafi T: Retrospective analysis of treatment of unresectable keloids with primary radiation over 25 years. Clin Oncol ( $R$ Coll Radiol) 2004, I 6(4):290-298.

23. Sallstrom KO, Larson O, Heden P, Eriksson G, Glas JE, Ringborg U: Treatment of keloids with surgical excision and postoperative X-ray radiation. Scand J Plast Reconstr Surg Hand Surg 1989, 23(3):2II-2I5.

\section{Pre-publication history}

The pre-publication history for this paper can be accessed here:

http://www.biomedcentral.com/1471-5945/6/7/prepub

Publish with Biomed Central and every scientist can read your work free of charge

"BioMed Central will be the most significant development for disseminating the results of biomedical research in our lifetime. "

Sir Paul Nurse, Cancer Research UK

Your research papers will be:

- available free of charge to the entire biomedical community

- peer reviewed and published immediately upon acceptance

- cited in PubMed and archived on PubMed Central

- yours - you keep the copyright

Submit your manuscript here:

http://www.biomedcentral.com/info/publishing_adv.asp
BiolMedcentral 